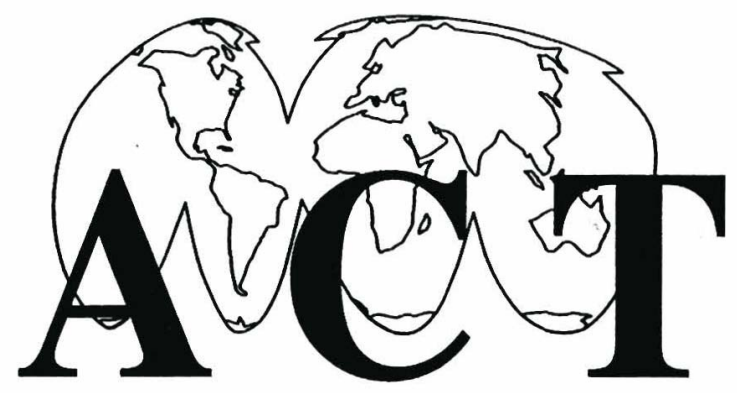

\title{
Application of spectral mixture analysis to Amazonian land-use and land-cover classification
}

\author{
D. Lu, M. Batistella, E. Moran and P. Mausel
}

Reprinted from:

International Journal of Remote Sensing. 10 December 2004. Vol. 25, No. 23. Taylor \& Francis Ltd. Pp. 5345-5358.

Anthropological Center for Training and Research on Global Environmental Change Indiana University, Student Building 331, 701 E. Kirkwood Ave., 47405-7100, U.S.A. Phone: (812) 855-6181, Fax: (812) 855-3000, Email: act@indiana.edu, internet: www.indiana.edu/ act 
INT. J. REMOTE SENSING, 10 DECEMBER, 2004,

vOL. 25 , NO. $23,5345-5358$

\title{
Application of spectral mixture analysis to Amazonian land-use and land-cover classification
}

\author{
D. LU†*, M. BATISTELLA $\ddagger$ E. MORAN $\uparrow \S$ and P. MAUSEL $\uparrow$ \\ †Center for the Study of Institutions, Population, and Environmental \\ Change (CIPEC), Indiana University, 408 North Indiana Avenue, \\ Bloomington, IN 47408, USA \\ $\ddagger$ Brazilian Agricultural Research Corporation, Embrapa Satellite Monitoring, \\ Campinas, SP 13088-300, Brazil \\ §Anthropological Center for Training and Research on Global Environmental \\ Change (ACT), Indiana University, Bloomington, IN 47405, USA \\ TDepartment of Geography, Geology, and Anthropology, Indiana State \\ University, Terre Haute, IN 47809, USA
}

(Received 12 March 2003; in final form 3 May 2004)

\begin{abstract}
Abundant vegetation species and associated complex forest stand structures in moist tropical regions often create difficulties in accurately classifying land-use and land-cover (LULC) features. This paper examines the value of spectral mixture analysis (SMA) using Landsat Thematic Mapper (TM) data for improving LULC classification accuracy in a moist tropical area in Rondônia, Brazil. Different routines, such as constrained and unconstrained least-squares solutions, different numbers of endmembers, and minimum noise fraction transformation, were examined while implementing the SMA approach. A maximum likelihood classifier was also used to classify fraction images into seven LULC classes: mature forest, intermediate secondary succession, initial secondary succession, pasture, agricultural land, water, and bare land. The results of this study indicate that reducing correlation between image bands and using four endmembers improve classification accuracy. The overall classification accuracy was $86.6 \%$ for the seven LULC classes using the best SMA processing routine, which represents very good results for such $a^{\circ}$ complex environment. The overall classification accuracy using a maximum likelihood approach was $81.4 \%$. Another finding is that use of constrained or unconstrained solutions for unmixing the atmospherically corrected or raw Landsat TM images does not have significant influence on LULC classification performances when image endmembers are used in a SMA approach.
\end{abstract}

\section{Introduction}

Land-use and land-cover (LULC) classification, especially for successional stages in a moist tropical region, is often difficult using medium spatial resolution data such as Landsat Thematic Mapper (TM) (Lu et al. 2003a). Per-pixel based classification approaches, such as the maximum likelihood classifier (MLC), which are based solely on spectral signatures for LULC classification, often result in poor

e-mail: dlu@indiana.edu

International Journal of Remote Sensing

ISSN 0143-1161 print/ISSN 1366-5901 online (C) 2004 Taylor \& Francis Ltd

hitp://www.tandf.co.uk/journals

DOI: $10.1080 / 01431160412331269733$ 


\section{D. $L u$ et al.}

accuracy ( $\mathrm{Lu}$ et al. 2004). The main reasons for this result are heterogeneity of vegetation structure, abundance of vegetation species, smooth transition between successional stages, and limited spatial resolution of remotely sensed data such as Landsat TM. Mixed pixels are common in medium spatial resolution remotely sensed data and such pixels have been recognized as a problem for remote sensing applications (Fisher 1997, Cracknell 1998). A mixed pixel is one in which more than one feature is present (e.g. $60 \%$ of a pixel might be forest and $40 \%$ might be soil resulting in a complex spectral signature). Spectral mixture analysis (SMA) has long been recognized as an effective method for ameliorating mixed pixel problems in remote sensing data and it has been proven to be helpful in improving classification accuracy (Adams et al. 1995, Roberts et al. 1998a, Shimabukuro et al. 1998, Lu et al. 2003a).

For many remote sensing applications, radiometric and atmospheric calibrations are often necessary and several different approaches have been used (Markham and Barker 1987, Chavez 1996, Stefan and Itten 1997, Vermote et al. 1997, Yang and Lo 2000, Song et al. 2001, Lu et al. 2002). Selecting a suitable atmospheric correction method is important for accurately converting digital number (DN) values into surface reflectance. However, in practice, because of lack of atmospheric data or time and cost constraints, much previous research did not implement atmospheric correction, or only converted DN values into radiance. In the SMA approach, some authors directly used DN or radiance (Cochrane and Souza 1998, Shimabukuro et al. 1998) and others used reflectance that was calibrated using different methods, such as the empirical-line method (Adams et al. 1995, Roberts et al. 1998a, Sabol et al. 2002), image-based dark object subtraction method (Novo and Shimabukuro 1997, Lu et al. 2003a), normalization of invariant objects between imageries (Elmore et al. 2000), and 6S (Ferrier et al. 2002). Another problem associated with image data is high correlation between adjacent wavelengths, for example, visible bands in Landsat TM or ETM + data. Some authors used the whole set of bands, while others used principal component analysis (PCA) or minimum noise fraction (MNF) to transform the original data to a new dataset to reduce the correlation and data redundancy (Garcia-Haro et al. 1996, Cochrane and Souza 1998, van der Meer and de Jong 2000, Small 2001). Comparative studies of impacts of radiometric and atmospheric correction and image transform methods on fraction image results are needed.

Endmember selection may be the most important aspect in SMA. Much research for endmember selection has been conducted (Smith et al. 1990, Adams et al. 1993, Roberts et al. 1993, Settle and Drake 1993, Bateson and Curtiss 1996, Tompkins et al. 1997, Garcia-Haro et al. 1999, Mustard and Sunshine 1999, Van der Meer 1999, Maselli 2001, Dennison and Roberts 2003). Lu et al. (2003a) and Theseira et al. (2003) summarized the major methods used in previous research. How many endmembers are required for a given study area and how to best identify them are two questions that need to be addressed initially. Ustin et al. (1996) indicate that regardless of the number of bands, only two to six endmembers are needed to characterize the overall variance in the image. Roberts et al. (1998b) found that two endmembers can model the majority of image scenes. In reality, three endmembers (e.g. green vegetation (GV), shade, and soil) and four endmembers (e.g. GV, shade, soil, and non-photosynthetic vegetation (NPV)) are often used (Smith et al. 1990, Adams et al. 1995, Cochrane and Souza 1998, Aguiar et al. 1999, Small 2001, Sabol et al. 2002). For many applications of SMA using remote sensing data, image endmembers are often used because they can be easily 


\section{SMA for land-use and land-cover}

obtained and they represent the spectra measured at the same scale as the image data (Roberts et al. 1998a). Image endmembers are derived from the extremes of the image feature space, assumed to represent the purest pixels in the images (Roberts et al. 1998a, Mustard and Sunshine 1999). However, if an image does not contain sufficiently pure examples of a specific material to allow its identification from the spectra of individual pixels, then it is necessary to use reference endmembers to link image endmembers with actual target materials (Roberts $e t$ al. 1993, Adams et al. 1995, Roberts et al. 1998a). Selecting reference endmembers from a spectral library or from field measurements is often flexible, but it is difficult to account for all possible features and processes due to different factors influencing the data spectra from spectral library information. At present, there is a lack of guidelines to identify which endmember selection method is most suitable for a specific study area, and different authors often use different methods. Selection of endmembers is often an iterative process. Evaluating the fraction images and residual images are prerequisite to refining endmembers. The characteristics of a study area and its scale are also important factors affecting the decision of endmember selection. An ideal endmember selection method should be easy to implement and to identify the true endmembers.

Although the SMA approach has been used for different applications, some important issues are still poorly understood. For example, is atmospheric correction of remotely sensed data required before using SMA? Can reduction of correlation between images improve fraction image quality? How many endmembers are suitable for LULC classification? Which unmixing solutions (i.e. constrained or unconstrained solution) can improve the quality of fraction images? The objectives of this paper attempt to answer these questions through a comparison of different image processing routines used in SMA for LULC classification in the Brazilian Amazon basin.

\section{A brief description of SMA}

SMA is regarded as a physically based image-processing tool. It supports repeatable and accurate extraction of quantitative subpixel information (Smith et al. 1990, Roberts et al. 1998a). The SMA approach assumes that the spectrum measured by a sensor is a linear combination of the spectra of all components within the pixel and the spectral proportions of the endmembers reflect proportions of the area covered by distinct features on the ground (Adams et al. 1995, Roberts et al. 1998a). The mathematical model can be expressed as

$$
R_{i}=\sum_{k=1}^{\ddot{n}} f_{k} R_{i k}+\varepsilon_{i}
$$

where $i$ is the spectral band used; $k=1, \ldots, n$ (number of endmembers); $R_{i}$ is the spectral reflectance of band $i$ of a pixel, which contains one or more endmembers;

$f_{k}$ is the proportion of endmember $k$ within the pixel; $R_{i k}$ is known as the spectral reflectance of endmember $k$ within the pixel on band $i$, and $\varepsilon_{i}$ is the error for band $i$.

In theory, in order to solve $f_{k}$, the following conditions should be met: (1) selected endmembers should not be a linear combination of each other, (2) the number of endmembers should be less than or equal to the spectral bands used, and (3) the spectral bands selected for analysis should not be highly correlated. Two methods, i.e. constrained (Garcia-Haro et al. 1996, Aguiar et al. 1999) and unconstrained solutions (van der Meer and de Jong 2000) are often used to unmix 
the linear mixture models. For a constrained unmixing solution, $f_{k}$ is subject to the following restrictions: $\sum_{k=1}^{n} f_{k}=1$ and $0 \leq f_{k} \leq 1$.

For the unconstrained solution, the fraction $f_{k}$ may assume negative values and is not constrained to sum to one. Therefore, the results from the unconstrained solution do not reflect the true abundance fractions of endmembers.

\section{Study area}

Rondônia has experienced high deforestation rates during the past two decades (INPE 2002). Following the national strategy of regional occupation and development, colonization projects initiated by the Brazilian government in the 1970s played a major role in this process (Moran 1981). Most colonization projects in the state were designed to settle landless migrants. The settlers transformed the forested landscape into a patchwork of cultivated crops, pastures, and successional forests. The study area is located at Machadinho d'Oeste, northeastern Rondônia (figure 1). Deforestation began in this area in the late 1980s. Most of the successional forests are less than 10 years old. The terrain is undulated, ranging from 100 to $450 \mathrm{~m}$ above sea level. Several soil types were found, mainly alfisols, oxisols, ultisols, alluvial soils, and other less spatially represented associations (Bognola and Soares 1999). The climate in this study area is classified as equatorial hot and humid, with tropical transition. The well-defined dry season lasts from June

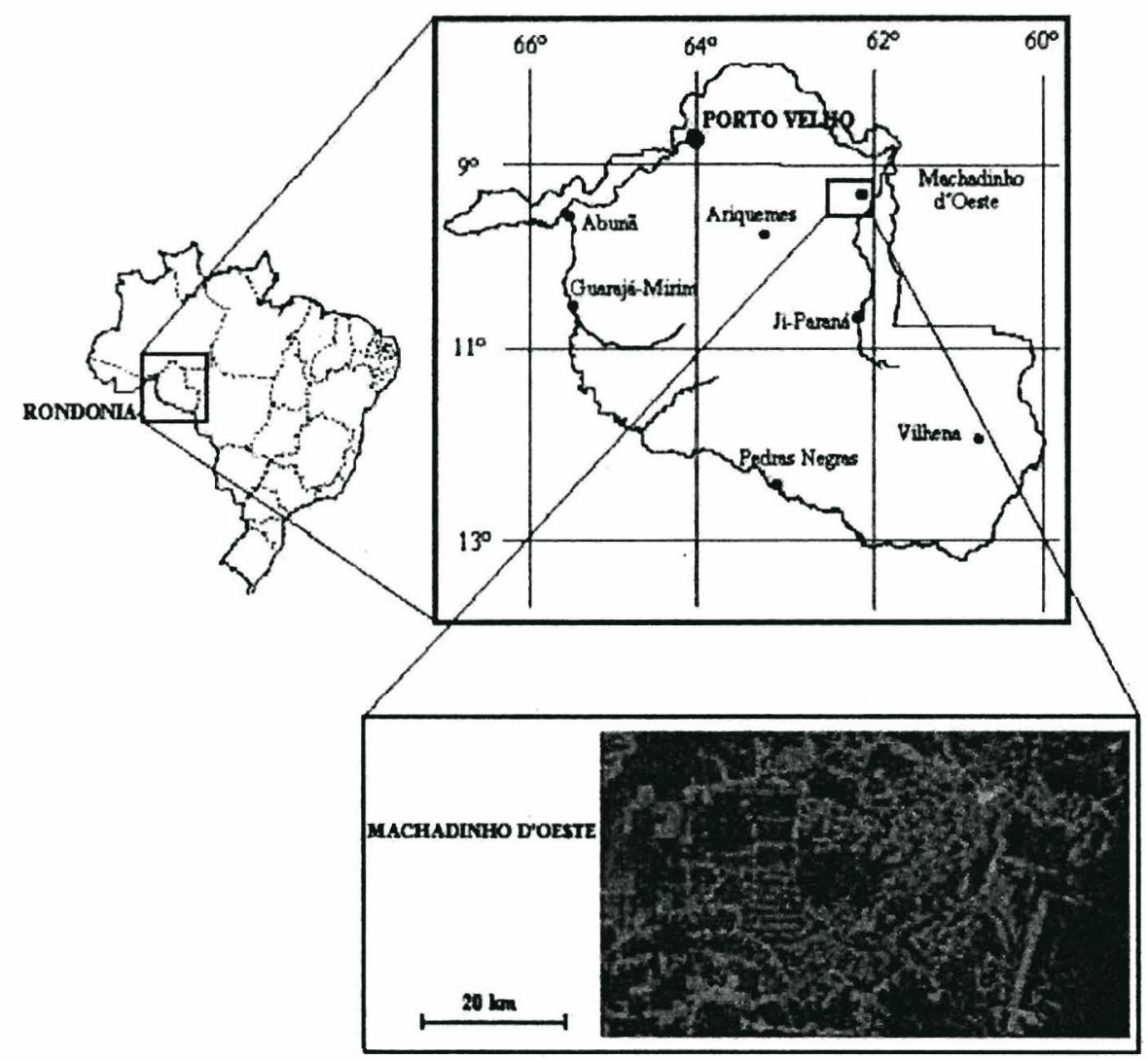

Figure 1. Location of the study area in Rondônia, Brazilian Amazon basin. 
to August. The annual average precipitation is $2016 \mathrm{~mm}$ and annual average temperature is $25.5^{\circ} \mathrm{C}$ (Rondônia 1998).

\section{Methods}

\subsection{Data collection}

Fieldwork was conducted in August 1999 and August 2000. Preliminary image classification and band composite printouts identified candidate areas to be surveyed, and a flight over the areas provided visual insights about the size, condition, and accessibility of each site. After driving extensively throughout the settlements, field observations gave insight into the structure of regrowth stages, mainly regarding total height and ground cover of dominant species. The procedure used for surveying vegetation was a multilevel technique adapted from methods used by researchers at the Center for the Study of Institutions, Population, and Environmental Change (CIPEC) at Indiana University (CIPEC 1998). After defining the area to be surveyed (plot sample), three subplots were randomly installed to cover the variability within the plot sample. A plot is composed of three nested squares (figure 2): one for sampling ground cover and tree or woody climber species seedlings $\left(1 \mathrm{~m}^{2}\right)$; one for sampling sapling information $\left(9 \mathrm{~m}^{2}\right)$; and one for sampling trees and woody species $\left(100 \mathrm{~m}^{2}\right)$. The centre of each subplot was randomly selected. Seedlings were defined as young trees or shrubs with a maximum stem diameter less than $2.5 \mathrm{~cm}$. Saplings were defined as young trees with DBH (diameter at breast height) from $2.5 \mathrm{~cm}$ to less than $10 \mathrm{~cm}$. Trees were defined as woody plants with a DBH greater than or equal to $10 \mathrm{~cm}$. Height, stem height, and $\mathrm{DBH}$ were measured for all trees in the $100 \mathrm{~m}^{2}$ area. Height and DBH were measured for all saplings in the $9 \mathrm{~m}^{2}$ area. Ground cover estimation and counting of individuals were conducted for seedlings and herbaceous vegetation in the $1 \mathrm{~m}^{2}$ area. Every plot was registered with a global positioning system (GPS) device to allow further integration with spatial data in geographical information systems (GIS) and image processing systems. Forty plots and 120 subplots were measured during the fieldwork in 1999. Detailed information regarding data gathering can be found in Batistella (2001) and Lu et al. (2003b). The forest stand parameters were analysed and the sample data were classified as SS1, SS2, SS3, and mature forest. Based on the stand structure (average stand diameter, average stand height, aboveground biomass, etc.), more sample plots, covering different secondary succession (SS) stages and other LULC types, were collected during fieldwork in August 2000. The sample plots were also overlaid on the Landsat TM colour composite to check the reflectance characteristics and to adjust LULC types if needed, considering the difference between the dates of Landsat TM image acquisition and field data collection. The field data were randomly separated into two groups. One group was used for training data for supervised classification and another group for test data. IKONOS data (acquired on 28 May 2001) were also used to identify more test sites for classification accuracy assessment.

\subsection{Image preprocessing}

Accurate geometric rectification and atmospheric calibration are two important aspects of image preprocessing. In this research, Landsat TM data from 18 June 1998 were geometrically rectified using control points taken from topographic maps at 1:100000 scale (Universal Transverse Mercator (UTM), south 20 zone). A nearest-neighbour resampling technique was used and a root mean square error 
D. $L u$ et al.

Study area

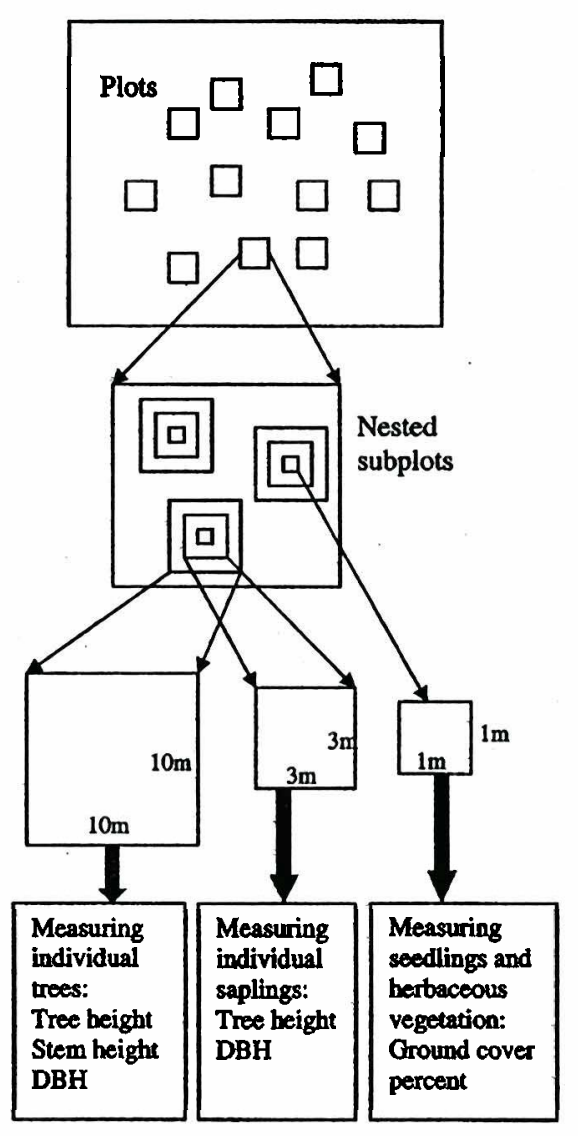

Figure 2. Strategy of field data collection for successional and mature forests. DBH, diameter at breast height.

with less than 0.5 pixel was obtained. The Landsat TM image was atmospherically calibrated using an improved image-based dark object subtraction (DOS) model (Lu et al. 2002). The gain and offset for each band and sun elevation angle were obtained from the image header file. The path radiance was identified based on clear water for each band. The atmospheric transmittance values for the visible and near infrared bands were derived from Chavez (1996), which were an average for each spectral band derived from radiative transfer code. For middle infrared bands, the atmospheric transmittance was set to 1 . The surface reflectance values after calibration fell within the range $0-1$. For the convenience of data analysis, the reflectance values were rescaled to range between 0 and 100 by multiplying by 100 for each pixel.

\subsection{Design of different processing routines}

In this study, endmembers were initially identified from the Landsat TM image based on ground truth data. The shade endmember was identified from the areas of clear and deep water, GV was selected from the areas of dense grass and pasture, and soil endmembers were selected from bare ground. The reflectances of these 


\section{SMA for land-use and land-cover}

initial endmembers were compared with those of the endmembers selected from the scatterplots of bands TM 3 and TM 4 and of bands TM 4 and TM 5. The endmembers whose curves are similar, but located at the vertices of the scatterplot, were finally selected. A MNF transformation was used to reduce data redundancy between image bands and to assist in endmember selection. Because the goal of this research is to find the most appropriate for LULC classification using a SMA approach, six different processing routines,'i.e. Raw_c, Ref_c, Ref_uc, MNF_c, Subset_c, and Subset_4c, were tested and their classification results compared. Figure 3 illustrates the six image processing approaches used for Amazonian LULC classification in this paper.

\subsection{Comparison of $L U L C$ classification results}

SMA can be regarded as an image-processing tool that converts a Landsat TM image into a physically-based fraction image. In order to assess objectively the capability of different processing methods in SMA, MLC was used to classify the fraction images into seven LULC classes: mature forest, intermediate secondary succession (SS2), initial secondary succession (SS1), pasture (including cultivated and degraded pastures), agriculture (including annual crops and perennial plantations), water, and bare land (including urban areas, roads and bare soil for cultivation). The same training sample dataset was used to implement supervised classification of each design of processing image, respectively.

After classification, an error matrix was used to assess classification accuracy. Overall accuracy (OA), producer's accuracy (PA), user's accuracy (UA), and kappa

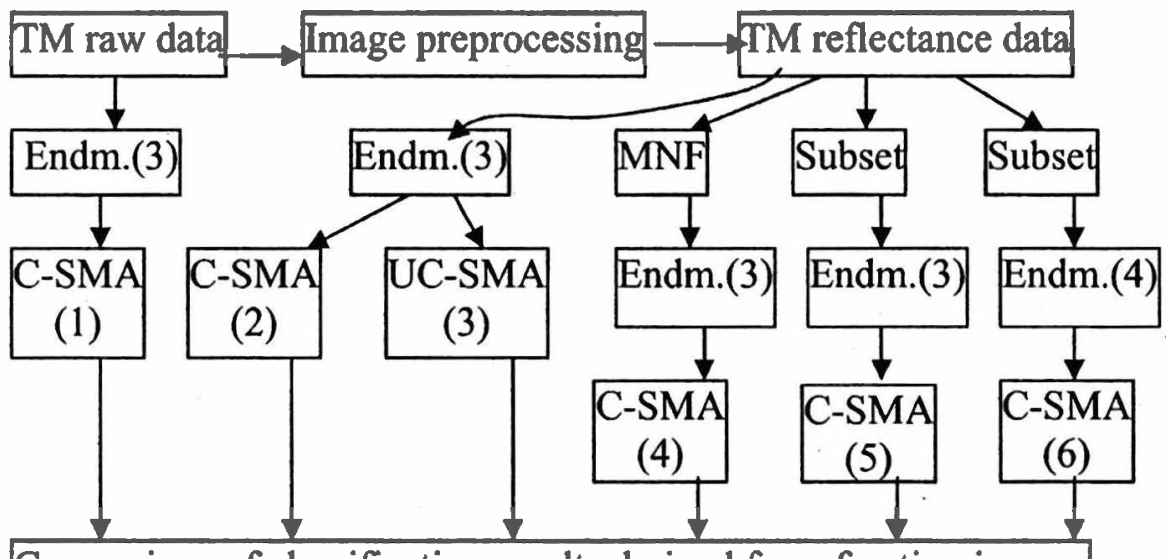

Comparison of classification results derived from fraction images

Figure 3. Different image-processing methods for LULC classification. (1) Raw-c (C-SMA_l): using constrained solution in SMA with three endmembers (i.e. shade, green vegetation and soil) on raw six-band Landsat TM data; (2) Ref-c (C-SMA_2): using constrained solution in SMA with three endmembers on six-band Landsat TM reflectance image; (3) Ref-uc (UC-SMA_3): using unconstrained solution in SMA with three endmembers on six-band Landsat TM reflectance image; (4) MNF-c (C-SMA_4): using constrained solution in SMA with three endmembers on the first four MNF components; (5) Subset-c (C-SMA_5): using constrained solution in SMA with three endmembers on bands Landsat TM 3, 4, 5, and 7; and (6) Subset-4c (C-SMA_6): using constrained SMA with four endmembers (i.e. green vegetation, shade, bright soil and dark soil) on bands TM 3, 4, 5, and 7 . 
coefficient were calculated for each classification method. KHAT, kappa variance, and Z-statistic were used to compare performance among different image processing routines. A total of 290 sample sites, covering different LULC types, were randomly allocated and examined using field data and IKONOS satellite data. A detailed description of the meanings and calculation methods for OA, PA, UA, and kappa coefficient or KHAT can be found in the literature (Congalton and Mead 1983, Congalton 1991, Janssen and van der Wel 1994, Smits et al. 1999, Foody 2002).

\section{Results}

\subsection{Characteristics of endmember fractions}

The endmember fractions were developed using SMA based on different image processing routines. Figure 4 gives an example illustrating the fraction characteristics of some typical LULC classes in the study area, using the Ref-c method. In the soil fraction, 'bare land' had significantly higher values while different successional and mature forests have very low soil fraction values. Pasture and agricultural lands have relative higher fraction values than those of successional and mature forests. In the GV fraction, water and bare land have small fraction values, as was anticipated. Mature forest has the lowest GV fraction values (after bare land and water) and SS1 has the highest GV fraction values. In the shade fraction, water has the highest value and bare land the lowest value. Mature forest has a significantly higher fraction value and SS1 and pastures have lower fraction values. SS2 and agriculture have lower values than mature forest but higher values than pasture and SS1. The error fraction indicates that high quality fraction images were obtained and the results were reliable because the error value for selected LULC classes was very small. Overall, water and bare land are the two classes that have the most different characteristics in the fraction image when compared with any other LULC classes. The distinction between vegetation types (SS and mature forest) and pasture or agricultural land is better depicted by the soil fraction, but the distinction between different SS stages and mature forest or between pasture and agriculture is better defined in the GV and shade fractions. Other fraction images derived from different image processing routines have similar trends in distinguishing LULC classes.

\subsection{Comparison of classification accuracies}

An error matrix for each classification method was produced. The UA, PA, OA and KHAT accuracy measurements were calculated based on each error matrix and were provided in table 1 and kappa analysis results were provided in table 2. Comparison of the results from atmospherically calibrated and raw images indicates that the Raw-c and Ref-c methods have similar classification accuracies (82.89\% versus $82.55 \%$ ) and similar KHAT coefficients (0.7854 versus 0.7792$)$. These results imply that atmospheric correction of Landsat TM bands does not improve LULC classification accuracy and such a correction is not required for SMA application to LULC classification. Although the Ref-c method produced a $1.09 \%$ higher overall classification accuracy than that of Ref_uc $(82.55 \%$ versus $81.46 \%$ ), the kappa analysis result indicated that they are not significantly different. This result suggests that using constrained or unconstrained solutions makes no significant difference in LULC classification accuracy.

Reducing correlation between image bands used in SMA, by using a MNF 


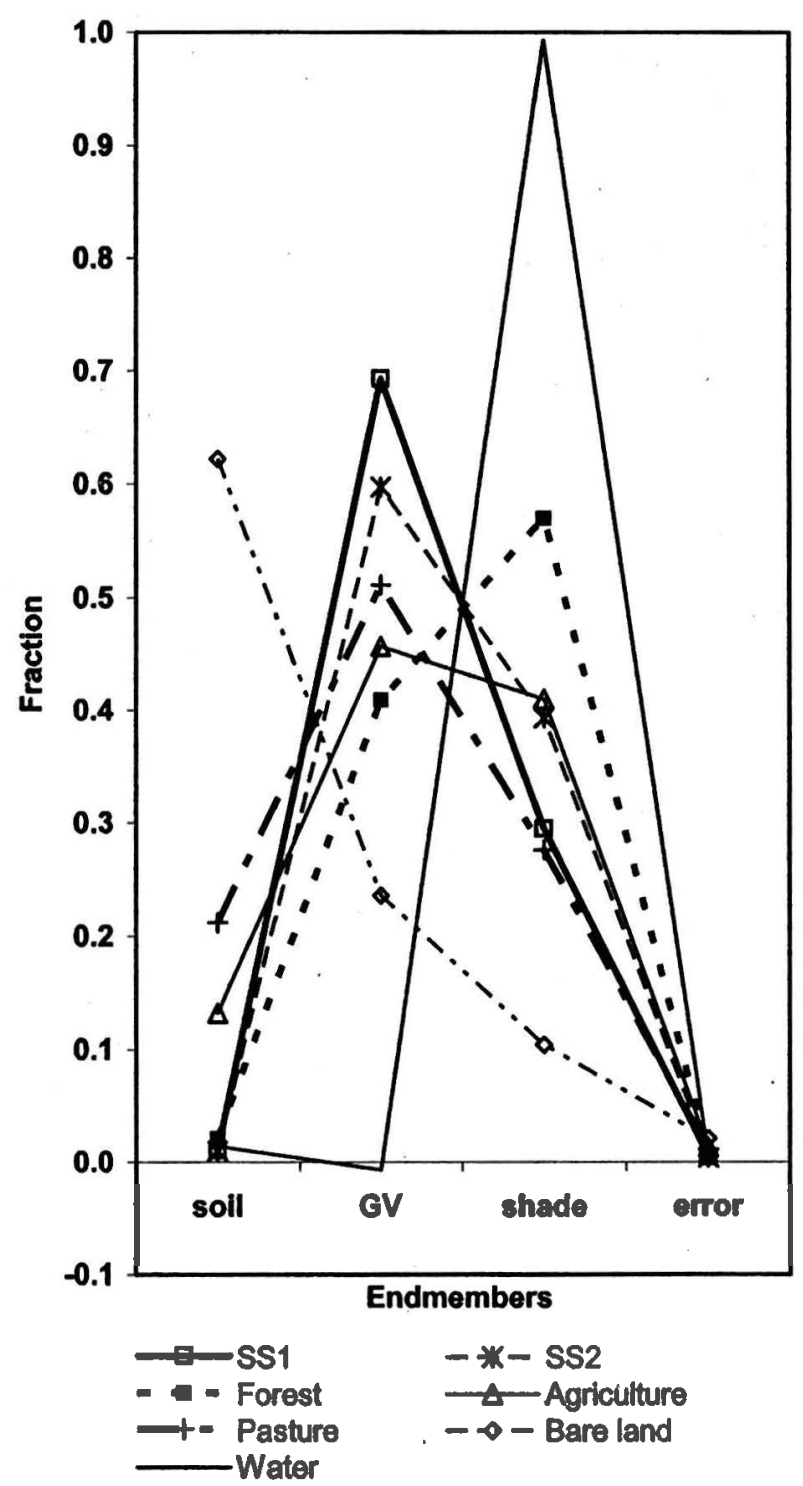

Figure 4. Fractions of typical LULC classes. SS1 —initial successional stage, SS2_intermediate successional stage.

image transformation and excluding use of bands TM 1 and TM 2, resulted in an overall classification accuracy increase of $1.4 \%$ compared with the Ref_c method. However, kappa analysis indicated that these results did not have significant difference with that of Ref_c. Analysis of the classification accuracies for each LULC class indicated that certain classes; such as pasture and bare land improved their classification accuracy. This implies that reducing correlation between images used in SMA may be helpful for improving spectral separability between selected LULC classes. Use of four endmembers associated with four image bands (i.e. Subset_4c approach) provided significantly better classification results than using Ref_c, Ref_uc, and MLC. The Subset-4c method mainly improved SS1, pasture, 
Table 1. Comparison of classification accuracy derived from different processing routines.

\begin{tabular}{|c|c|c|c|c|c|c|c|c|c|c|c|c|c|c|}
\hline \multirow{3}{*}{$\begin{array}{l}\text { Land cover } \\
\text { classes }\end{array}$} & \multirow{2}{*}{\multicolumn{2}{|c|}{$\begin{array}{l}\text { Based on Landsat } \\
\text { TM data }\end{array}$}} & \multicolumn{12}{|c|}{ Based on fraction images derived from different processing routines } \\
\hline & & & \multicolumn{2}{|c|}{ Raw-c } & \multicolumn{2}{|c|}{ Ref-c } & \multicolumn{2}{|c|}{ Ref-uc } & \multicolumn{2}{|c|}{ MNF-c } & \multicolumn{2}{|c|}{ Subset-c } & \multicolumn{2}{|c|}{ Subset $-4 c$} \\
\hline & UA & PA & UA & PA & UA & PA & UA & PA & UA & PA & UA & PA & UA & PA \\
\hline Forest & 94.38 & 98.82 & 96.59 & 100.00 & 96.59 & 100.00 & 92.39 & 100.00 & 96.55 & 97.67 & 96.59 & 100.00 & 96.55 & 98.82 \\
\hline SS2 & 31.82 & 53.85 & 34.78 & 50.00 & 33.33 & 57.14 & 37.50 & 56.25 & 37.50 & 52.94 & 38.46 & 58.82 & 35.71 & 66.67 \\
\hline SSI & 90.20 & 69.70 & 86.00 & 65.15 & 93.33 & 62.69 & 93.48 & 65.15 & 90.00 & 70.31 & 91.49 & 65.15 & 92.31 & 70.59 \\
\hline Pasture & 84.85 & 73.68 & 79.07 & 89.47 & 79.27 & 83.33 & 80.26 & 79.22 & 87.18 & 86.08 & 81.18 & 88.46 & 86.25 & 88.46 \\
\hline Agriculture & 82.76 & 77.42 & 85.19 & 76.67 & 77.42 & 80.00 & 78.13 & 78.13 & 68.57 & 82.76 & 82.76 & 80.00 & 86.67 & 89.66 \\
\hline Bare land & 88.88 & 100.00 & 84.74 & 94.74 & 75.00 & 94.74 & 67.86 & 95.00 & 85.71 & 94.74 & 85.71 & 94.74 & 100.00 & 88.89 \\
\hline Water & 100.00 & 83.33 & 100.00 & 83.33 & 100.00 & 80.00 & 100.00 & 66.67 & 100.00 & 80.00 & 100.00 & 80.00 & 100.00 & 100.00 \\
\hline $\mathrm{OA}$ & \multicolumn{2}{|c|}{$81.42^{05.50}$} & \multicolumn{2}{|c|}{82.89} & \multicolumn{2}{|c|}{82.55} & \multicolumn{2}{|c|}{81.46} & \multicolumn{2}{|c|}{$84.28^{\circ 0.00}$} & \multicolumn{2}{|c|}{84.33} & \multicolumn{2}{|c|}{86.58} \\
\hline KHAT & \multicolumn{2}{|c|}{0.7668} & \multicolumn{2}{|c|}{0.7854} & \multicolumn{2}{|c|}{0.7792} & \multicolumn{2}{|c|}{0.7667} & \multicolumn{2}{|c|}{0.8013} & \multicolumn{2}{|c|}{0.8016} & \multicolumn{2}{|c|}{0.8298} \\
\hline
\end{tabular}

UA, user's accuracy; PA, producer's accuracy; OA, overall accuracy (\%). 
Table 2. Comparison of kappa analysis results among different methods.

\begin{tabular}{lcccccc}
\hline Method & Code & KHAT & Variance & Combination & Z-statistic & Result \\
\hline Subset-4c & $(1)$ & 0.8298 & 0.000608 & (1) versus (7) & 1.7001 & S_90\% \\
Subset-c & $(2)$ & 0.8016 & 0.000679 & (1) versus (6) & 1.7073 & S_90\% \\
MNF-c & $(3)$ & 0.8013 & 0.000678 & (1) versus (5) & 1.3794 & S_80\% \\
Raw-c & $(4)$ & 0.7854 & 0.000714 & (1) versus (4) & 1.2203 & NS \\
Ref-c & $(5)$ & 0.7792 & 0.000739 & (2) versus (7) & 0.9152 & NS \\
Ref-uc & $(6)$ & 0.7667 & 0.000756 & (2) versus (6) & 0.9195 & NS \\
MLC & $(7)$ & 0.7668 & 0.000765 & (3) versus. (7) & 0.9076 & NS \\
\hline
\end{tabular}

S_90\% and S_80\% indicate significant at $90 \%$ and $80 \%$ confidence levels, respectively. NS indicates non-significant.

and agriculture accuracies. This result indicates that adding one more soil endmember can improve the classification accuracy for those classes whose soil conditions have serious impacts on their reflectance values.

Overall, Subset-4c, Subset-c, and MNF-c methods provided higher KHAT values (greater than 0.8 ) associated with slightly smaller kappa variances compared to the other methods used. In particular, Subset-4c had significantly better classification performance than Ref-c, Ref-uc, and MLC. All other methods do not show a significant difference in classification performance. These results suggest that selecting suitable image bands and endmembers are the two most important elements needed for improving LULC classification accuracy when using SMA for LULC classification in moist tropical areas of the Brazilian Amazon basin.

\section{Discussion and conclusions}

The results of this research indicated that high confusion exists among SS1, SS2, pasture (e.g. degraded pasture), and agriculture (e.g. coffee plantation) classes. In the study area, the majority of successional vegetation was less than 10 years old on the 1998 Landsat TM image. Most of the SS2 vegetation was between 6-10 years old and most of SS1 was less than 5 years. In practice, the transition between SS1 and SS2 is very smooth and no distinct boundary exists. Also, SS1 is often confused with degraded pasture and some perennial crops such as coffee plantations. The confusion between bare land and pasture becomes exacerbated by overgrazing during the dry season, when soil spectral response contributes more significantly to the signature of sparsely covered grassy vegetation. Conversely, degraded pasture which is in the process of vegetation recovery often has high densities of Vismia sp. and Orbignya sp., thereby increasing its confusion with the spectral response for SS1 or even perennial agriculture. Spectral responses for perennial agriculture can also be confused with SS1, mainly in areas of initial recovery of disturbed gallery vegetation.

In moist tropical forest areas, vegetation stand structure and species composition are very complex. For an optical satellite sensor such as Landsat TM, the sensor mainly captures information from the leaves, wood, and shadowing information for a dense vegetation area. However, for sparse vegetation, soil and litter also can significantly affect reflectance. In a large study area, soil conditions can be different and consequently the impacts of soil on feature reflectance can vary greatly. Not all components selected are resolvable in a given image because of the nature of their mixing and the degree of spectral contrasts found within pixels. Thus, different research questions and different characteristics of the selected study 
area will require use of different endmembers. For example, the endmembers may be different for forest dominant regions, agricultural dominant regions and urban dominant regions.

The selection of endmembers can be refined based on the analysis of the error fraction or unmodelled spectral variance. For Landsat TM images, selecting more than four endmembers is often difficult when using image endmembers. Also, high correlation between Landsat TM bands limits the number of endmembers to be used in the SMA. However, reducing the correlation among the images used results in an improvement of the fraction image and LULC classification accuracy. Linear transforms such as PCA and MNF are often used to reduce the correlation between images. This is especially necessary when hyperspectral data are used in a SMA.

In summary, analysis of the classification results indicated that neither constrained nor unconstrained least squares solutions and neither atmospherically corrected nor raw Landsat TM images produced significantly different classification accuracies. However, reducing band correlations using the MNF transformation or using Landsat TM band subset images (i.e. bands TM 3, 4, 5, and 7) and four endmembers (i.e. GV, shade, bright soil, and dark soil) improved classification accuracy. The classification accuracies range from $84.28 \%$ to $86.58 \%$ for these SMA routines. Selecting endmembers appropriately and reducing correlation between image bands used are two crucial aspects for developing high quality fraction images when SMA is used for LULC classification. This paper contributes to the search for better techniques to classify LULC features in complex environments such as those found within the Brazilian Amazon basin.

\section{Acknowledgments}

The authors wish to thank the National Science Foundation (grants 95-21918 and 99-06826), the National Aeronautics and Space Administration (grant N005334), and Brazil's Embrapa Satellite Monitoring for their support. This project is part of the Large-Scale Biosphere Atmosphere Experiment in Amazonia (LBA) Program, LC-09, which aims to examine the human and physical dimensions of LULC change.

\section{References}

AdAMS, J. B., Smith, M. O., and Gillespie, A. R., 1993, Imaging spectroscopy: interpretation based on spectral mixture analysis. In Remote Geochemical Analysis: Elemental and mineralogical composition, edited by C. M. Pieters and P. A. J. Englert (New York: Cambridge University Press), pp.145-166.

Adams, J. B., Sabol, D. E., Kapos, V., Filho, R. A., RoberTs, D. A., SMITH, M. O., and GiLLESPIE, A. R., 1995, Classification of multispectral images based on fractions of endmembers: application to land cover change in the Brazilian Amazon. Remote Sensing of Environment, 52, 137-154.

Aguiar, A. P. D., Shimabukuro, Y. E., and Mascarenhas, N. D. A., 1999, Use of synthetic bands derived from mixing models in the multispectral classification of remote sensing images. International Journal of Remote Sensing, 20, 647-657.

BATESON, A., and CURTISS, B., 1996, A method for manual endmember selection and spectral unmixing. Remote Sensing of Environment, 55, 229-243.

BAtistella, M., 2001, Landscape change and land-use/land-cover dynamics in Rondônia, Brazilian Amazon. PhD dissertation, Indiana University, Bloomington, Indiana, USA.

Bognola, I. A., and Soares, A. F., 1999, Solos das 'glebas 01, 02, 03 e 06' do Municipio de Machadinho d'Oeste, RO. Pesquisa em Andamento, n.10, EMBRAPA Monitoramento por Satélite, Campinas, Brazil, 7 p. 
Chavez, P. S. JR, 1996, Image-based atmospheric corrections-revisited and improved. Photogrammetric Engineering and Remote Sensing, 62, 1025-1036.

CIPEC (Center for the Study of Institutions, Population, and Environmental Change), 1998, International Forestry Resources and Institutions (IFRD) Research Program, Field Manual. CIPEC, Indiana University, $273 \mathrm{p}$.

Cochrane, M. A., and SouzA, C. M. JR, 1998, Linear mixture model classification of burned forests in the eastern Amazon. International Journal of Remote Sensing, 19, 3433-3440.

CONGALton, R. G., 1991, A review of assessing the accuracy of classification of remotely sensed data. Remote Sensing of Environment, 37, 35-46.

Congalton, R. G., and MeAD, R. A., 1983, A quantitative method to test for consistency and correctness in photo interpretation. Photogrammetric Engineering and Remote Sensing, 49, 69-74.

CRACKNEll, A. P., 1998, Synergy in remote sensing-what's in a pixel? International Journal of Remote Sensing, 19, 2025-2047.

DENNISON, P. E., and ROBERTS, D. A., 2003, Endmember selection for multiple endmember spectral mixture analysis using endmember average RMSE. Remote Sensing of Environment, 87, 123-135.

Elmore, A. J., Mustard, J. F., Manning, S. J., and Lobell, D. B., 2000, Quantifying vegetation change in semiarid environments: precision and accuracy of spectral mixture analysis and the normalized difference vegetation index. Remote Sensing of Environment, 73, 87-102.

Ferrier, G., White, K., Griffiths, G., Bryant, R., and Stefouli, M., 2002, The mapping of hydrothermal alteration zones on the island of Lesvos, Greece using an integrated remote sensing dataset. International Journal of Remote Sensing, 23, 341-356.

FisHER, P., 1997, The pixel: a snare and a delusion. International Journal of Remote Sensing, 18, 679-685.

F.oDy, G. M., 2002, Status of land cover classification accuracy assessment. Remote Sensing of Environment, 80, 185-201.

Garcia-Haro, F. J., Gilabert, M. A., and Melia, J., 1996, Linear spectral mixture modeling to estimate vegetation amount from optical spectral data. International Journal of Remote Sensing, 17, 3373-3400.

Garcia-Haro, F. J., Gilabert, M. A., and Melia, J., 1999, Extraction of endmembers from spectral mixtures. Remote Sensing of Environment, 68, 237-253.

Instituto Nacional De Pesquisas EsPaciaIs (INPE), 2002, Monitoring of the Brazilian Amazon Forest by Satellite 2000-2001 (São Paulo: INPE).

JANSSEN, L. F. J., and VAN DER WEL, F. J. M., 1994, Accuracy assessment of satellite derived land-cover data: a review. Photogrammetric Engineering and Remote Sensing, 60, 419-426.

Lu, D., Mausel, P., Brondizio, E. S., and MORAN, E., 2002, Assessment of atmospheric correction methods for Landsat TM data applicable to Amazon basin LBA research. International Journal of Remote Sensing, 23, 2651-2671.

Lu, D., Moran, E., and Batistella, M., 2003a, Linear mixture model applied to Amazônian vegetation classification. Remote Sensing of Environment, 87, 456-469.

Lu, D., Batistella, M., and MORAN, E., 2003b, Integration of vegetation inventory data and Thematic Mapper image for Amazonian successional and mature forest classification. Proceedings of the 2003 ASPRS Annual Conference, 5-9 May, Anchorage, Alaska (Bethesda, MD: American Society of Photogrammetry and Remóte Sensing), CD Rom.

Lu, D., Mausel, P., Batistella, M., and Moran, E., 2004, Comparison of land-cover classification methods in the Brazilian Amazon basin. Photogrammetric Engineering and Remote Sensing, 70, 723-731.

MARKhAM, B. L., and BARKER, J. L., 1987, Thematic Mapper bandpass solar exoatmospheric irradiances. International Journal of Remote Sensing, 8, 517-523.

MASELLI, F., 2001, Definition of spatially variable spectral endmembers by locally calibrated multivariate regression analysis. Remote Sensing of Environment, 75, 29-38.

MORAN, E. F., 1981, Developing the Amazon (Bloomington, IN: Indiana University Press).

MUSTARD, J. F., and Sunshine, J. M., 1999, Spectral analysis for earth science: investigations using remote sensing data. In Remote Sensing for the Earth Sciences: 
Manual of remote sensing, 3rd edn, vol.3, edited by A. N. Rencz (New York: John Wiley \& Sons), pp. 251-307.

Novo, E. M., and SHIMABUKURO, Y. E., 1997, Identification and mapping of the Amazon habitats using a mixing model. International Journal of Remote Sensing, 18, 663-670.

ROBERTS, D. A., SMITH, M. O., and ADAMS, J. B., 1993, Discriminating green vegetation, non-photosynthetic vegetation, and soils in AVIRIS data. Remote Sensing of Environment, 44, 255-269.

Roberts, D. A., Batista, G. T., Pereira, J. L. G., Waller, E. K., and Nelson, B. W., 1998a, Change identification using multitemporal spectral mixture analysis: applications in eastern Amazonia. In Remote Sensing Change Detection: Environmental Monitoring Methods and Applications, edited by R. S. Lunetta and C. D. Elvidge (Chelsea, MI: Ann Arbor Press), pp.137-161.

Roberts, D. A., Gardner, M., Church, R., Ustin, S., Scheer, G., and Green, R. O., 1998b, Mapping chaparral in the Santa Monica mountains using multiple endmember spectral mixture models. Remote Sensing of Environment, 65, 267-279.

RonDónIA, 1998, Diagnóstico sócio-econômico do Estado de Rondônia e assistência técnica para formulação da segunda aproximação do zoneamento sócio-econômico-ecológicoClimatologia, v.1. Porto Velho, Governo de Rondônia/PLANAFLORO, 401 p.

Sabol, D. E. JR, Gillespie, A. R., Adams, J. B., Smith, M. O., and TuCKER, C. J., 2002, Structural stage in Pacific Northwest forests estimated using simple mixing models of multispectral images. Remote Sensing of Environment, 80, 1-16.

Settle, J. J., and DRAKE, N. A., 1993, Linear mixing and the estimation of ground cover proportions. International Journal of Remote Sensing, 14, 1159-1177.

Shimabukuro, Y. E., Batista, G. T., Melio, E. M. K., Moreira, J. C., and Duarte, V., 1998, Using shade fraction image segmentation to evaluate deforestation in Landsat Thematic Mapper images of the Amazon region. International Journal of Remote Sensing, 19, 535-541.

SMALL, C., 2001, Estimation of urban vegetation abundance by spectral mixture analysis. International Journal of Remote Sensing, 22, 1305-1334.

Smith, M. O., Ustin, S. L., AdAms, J. B., and Gillespie, A. R., 1990, Vegetation in Deserts: I. A regional measure of abundance from multispectral images. Remote Sensing of Environment, 31, 1-26.

Smits, P. C., Dellepiane, S. G., and Schowengerdt, R. A., 1999, Quality assessment of image classification algorithms for land-cover mapping: a review and a proposal for a cost-based approach. International Journal of Remote Sensing, 20, 1461-1486.

Song, C., Woodcock, C. E., Seto, K. C., LenNey, M. P., and Macomber, S. A., 2001, Classification and change detection using Landsat TM data: when and how to correct atmospheric effect? Remote Sensing of Environment, 75, 230-244.

STEFAN, S., and ITTEN, K. I., 1997, A physically-based model to correct atmospheric and illumination effects in optical satellite data of rugged terrain. IEEE Transactions on Geoscience and Remote Sensing, 35, 708-717.

Theseira, M. A., Thomas, G., Taylor, J. C., Gemmell, F., and Varjo, J., 2003, Sensitivity of mixture modeling to endmember selection. International Journal of Remote Sensing, 24, 1559-1575.

Tompkins, S., Mustard, J. F., Pieters, C. M., and Forsyth, D. W., 1997, Optimization of endmembers for spectral mixture analysis. Remote Sensing of Environment, 59, 472-489.

Ustin, S. L., HART, Q. J., DuAN, L., and SCHEeR, G., 1996, Vegetation mapping on hardwood rangelands in California. International Journal of Remote Sensing, 17, 3015-3036.

VAN DER MEER, F., 1999, Iterative spectral unmixing (ISU). International Journal of Remote Sensing, 20, 3431-3436.

VAN DER MEER, F., and DE JONG, S. M., 2000, Improving the results of spectral unmixing of Landsat Thematic Mapper imagery by enhancing the orthogonality of end-members. International Journal of Remote Sensing, 21, 2781-2797.

Vermote, E., Tanre, D., Deuze, J. L., Herman, M., and Morcrette, J. J., 1997, Second simulation of the satellite signal in the solar spectrum, 6S: an overview. IEEE Transactions on Geoscience and Remote Sensing, 35, 675-686.

YANG, X., and Lo, C. P., 2000, Relative radiometric normalization performance for change detection from multi-date satellite images. Photogrammetric Engineering and Remote Sensing, 66, 967-980. 


\section{ACT Publications 2003}

\section{No. 03-01}

Moran, E., A. Siqueira and E. Brondizio. "Household Demographic Structure and it's Relationship to Deforestation in the Amazon Basin." People and the Environment: Approaches to Linking Household and Community Surveys to Remote Sensing and GIS. J. Fox, V. Mishra, R. Rindfuss, and S. Walsh (eds.) 2003. Kluwer Academic Press. Pp. 130.

No 03-02

Batistella, M., S. Robeson, E. Moran. "Settlement Design, Forest Fragmentation, and Landscape Change in Rodonia, Amazonia." Photogrammetiric Engineering \& Remote Sensing Vol. 69(7), July 2003, pp. 805-812.

No $03-03$

Lu, D., P. Mausel, E. Brondizio, E. Moran. "Classification of successional forest stages in the Brazilian Amazon basin." Forest Ecology and Management Vol. 181, pp. 301-312. (2003).

No 03-04

Futemma, C., E. Brondizio. "Land Reform and Land-Use Changes in the Lower Amazon: Implications for Agricultural Intensification." Human Ecology Vol. 31(3) September 2003. Pp. 369-402.

No 03-05

Siqueira, A., S. McCracken, E. Brondizio, E. Moran. "Women and Work in a Brazilian Agricultural Frontier." In: Gender at Work in Economic Life. Gracia Clark (editor). 2003. Altamira Press, New York, NY. Pp. 243-265.

No 03-06

Hurtt, G.; X. Xiao, M. Keller, M. Palace, G. Asner, R. Braswell Eduardo Brondizio, Scott Hetrick et al. "IKONOS imagery for the Large Scale Biosphere-Atmosphere Experiment in Amazonia (LBA)." Remote Sensing of Environment 88(2003). Pgs 111-127.

No 03-07

Lu, Densheng; Emilio Moran, and Mateus Batistella. "Linear mixture model applied to Amazonian vegetation classification." Remote Sensing of Environment 87(2003). Pgs 456-469. 